\title{
IAC 25 (PEDRINHAS) E IAC 161 (TAIAMÃ): NOVOS CULTIVARES DE TRIGO(1)
}

\author{
JOÃO CARLOS FELICIO $(2,5)$, CARLOS EDUARDO DE OLIVEIRA CAMARGO $(2,5)$, \\ ANTONIO WILSON PENTEADO FERREIRA FILHO $(2,5)$, POLICARPO VITTI $(4,5)$ \\ e PAULO BOLLER GALLO (3)
}

\begin{abstract}
RESUMO
Avaliaram-se os cultivares de trigo IAC 25 (Pedrinhas) e IAC 161 (Taiamă), provenientes de cruzamentos artificiais e obtidos por seleçăo pelo método genealógico, quanto à produtividade de grãos e às reaçōes aos agentes causais da ferrugem-do-colmo e da-folha e da helmintosporiose no Vale do Paranapanema (SP), em condiçбes de sequeiro, e na regiåo Norte (SP), com irrigação por aspersão. Avaliaram-nos tambêm em relação às qualidades industriais de panificação. Em condiçðes de sequeiro, as produçőes médias de grăos dos novos cultivares năo se apresentaram estatisticamente diferentes das da testemunha 'Anahuac', porêm 'Pedrinhas' confirmou como grande vantagem o ciclo precoce (100-115 dias). Para as áreas com irrigaçáo por aspersão, em solos com elevada acidez (porcentagem de saturação por bases inferior a 60\%) 'Peơrinhas' e Taiamã' exibiram melhor produçăo de grăos em relação ao 'Anahuac'. Para.solos com baixa acidez, não houve diferença estatlstica entre os três cultivares. $O$ 'Pedrinhas' e 0 'Taiamă' apresentaram moderada toleråncia ao $\mathrm{Al}^{3+}$, quando testados em soluçס́es nutritivas contendo esse ejemento; 'Taiamă' demonstrou alta suscetibilidade à toxicidade de ferro e, 'Pedrinhas', moderada toleráncia, enquanto para o manganês ambos exibiram tolerância. $O$ 'Taiamă' mostrou resistência à ferrugem-do-colmo e, o 'Pedrinhas', moderada resistência, em testes em casa de vegetaçăo. $O$ 'Pedrinhas' revelou-se mais suscetivel à ferrugem-da-folha que o 'Taiamă' e o 'Anahuac' em condiçסes de campo, enquanto, para a helmintosporiose, os três apresentaram-se suscetiveis. Nos
\end{abstract}

(1) Com verba suplementar do Acordo entre as Cooperativas de Produtores Rurais do Vale do Paranapanema e a Secretaria de Agricultura e Abastecimento, por intermédio do Instituto Agronómico. Recebido para publicaçăo em 5 de jutho de 1989 e aceito em 3 de abril de 1990.

(2) Seçăo de Arroz e Cereais de Inverno, Instituto Agronómico (IAC), Caixa Postal 28, 13001 Campinas (SP).

(3) Estaçăo Experimental de Mococa, IAC.

(4) Seçáo de Cereais, Farinhas e Panificaçăo, Instituto de Tecnologia de Alimentos (ITAL), Caixa Postal 139, 13001 Campinas (SP)

(5) Com bolsa de pesquisa do CNPq. 
ensaios de panificaçăo, a farinha do 'Taiamá' foi superior à do 'Pedrinhas', proporcionando pães de excelente qualidade tfsica, com volume especfico bastante superior à farinha de trigo comercial.

Termos de indexaçăo: cultura de trigo de sequeiro e irrigada; raças fisiologicas de ferrugem; resistencia às moléstias; caracteristicas de panificaçăo.

\section{ABSTRACT}

\section{IAC 25 (PEDRINHAS) AND IAC 161 (TAIAMĀ): NEW WHEAT CULTIVARS}

The wheat cultivars IAC 25 (Pedrinhas) and IAC 161 (Taiamã) originated from artificial crosses and selected by the pedigree method, were evaluated in relation to grain yield and to reactions of the causal agents of leaf and stem rusts and to Helminthosporium sp. These cultivars were also evaluated in relation to industrial bread qualities. The trials were carried out in upland conditions at the Paranapanema Valley, State of Sảo Paulo, Brazil, and also under sprinkler irrigation at the North region of the same State. Grain yield of the new cultivars did not show significant differences from 'Anahuac' used as a control in upland conditions. However, in this condition, 'Pedrinhas' showed the advantage of being an early cultivar (100-115 days from emergence to maturation). Under sprinkler irrigation and acid soil conditions, 'Pedrinhas' and 'Taiamå' presented higher grain yield than 'Anahuac'; on low acidity soils no differences were observed among cultivars in relation to grain yield. In nutrient solution tests, 'Pedrinhas' and 'Taiamă' were moderately tolerant to $\mathrm{Al}^{3+}$; 'Taiamã' was highly sensitive to iron excess and 'Pedrinhas' moderately tolerant; and both cultivars were tolerant to manganese excess. Under greenhouse conditions 'Taiamă' presented resistance and 'Pedrinhas' moderate resistance to stem rust. 'Pedrinhas' was more susceptible to leaf rust than 'Taiamă' and 'Anahuac'; and the three cultivars were susceptible to Helminthosporium sp. under field conditions. Considering bread characteristics trials the flour from 'Taiamă' was superior in relation to 'Pedrinhas', giving breads with excellent physical quality, showing a superior specific volume in comparison with the breads made with commercial wheat flour.

Index terms: wheat crop, upland condition, sprinkler irrigation condition; rust, physiological races; disease resistance; bread characteristics.

\section{INTRODUÇĀO}

O melhoramento do trigo no Brasil vem sendo conduzido com um nivel de eficiência satisfatório em muitos aspectos, porém está aquém das necessidades do País, devido à dificuldade de adaptar esta espécie às condiçōes ambientais diferentes de onde ela vem sendo cultivada há muitos séculos (SILVA, 1966). 
Tem sido atribuído ao clima uma das causas das grandes variações de rendimento na cultura do trigo, porém existem muitas maneiras de minimizar-lhe os efeitos. A coleção mundial de germoplasma de trigo contém variedades que variam quanto à tolerância ao frio, à geada, ao calor, aos ventos quentes e secos, a periodos de seca de diversas duraçōes em fases distintas de crescimento da planta (HANSON et al., 1982), as quais poderiam ser utilizadas como fontes genéticas no programa de melhoramento.

Segundo HANSON et al. (1982), o potencial genético de rendimento dos trigos de primavera tem sido incrementado gradualmente desde os primeiros anos da década de 1960, isto é, desde que se duplicou o rendimento potencial com os genótipos do tipo semi-anão.

No Brasil, a ferrugem-do-colmo (OSÓRIO, 1982) não tem sido tão problemática à triticultura como nas regiōes produtoras de outros países. As epifitias constatadas não têm sido fatores adversos à cultura e as variedades suscetiveis têm sido substituidas por outras, resistentes às novas raças surgidas.

Atualmente, a helmintosporiose vem prejudicando, de forma generalizada, a cultura do trigo no Brasil: favorecida por elevadas temperaturas (25 a $30^{\circ} \mathrm{C}$ ) e alta umidade, tem aparecido com maior intensidade nas regiōes tritícolas do norte do Paraná, embora em alguns anos tenha causado fortes epifitias em regiōes mais frias, do extremo sul do País (OSÓRIO, 1982).

FELÍClO et al. (1983, 1985 e 1988), mediante trabalhos de melhoramento genético, vêm selecionando novos cultivares de trigo no Instituto Agronômico de Campinas, mais adaptados às condiçōes de clima e solo da regiáo tritícola situada ao norte do paralelo $24^{\circ} \mathrm{S}$., destacando-se: IAC 17 (Maracaí), IAC 18 (Xavantes), IAC 21 (Iguaçu), IAC 22 (Araguaia), IAC 23 (Tocantins) e IAC 24 (Tucurui), este último de porte semi-anāo e com tolerância ao $\mathrm{Al}^{3+}$.

O presente trabalho tem por objetivo estudar o comportamento de dois novos cultivares de trigo, IAC 25 (Pedrinhas) e IAC 161 (Taiamã) nas condiçōes de sequeiro e de irrigação por aspersāo, no Estado de São Paulo, ao norte do paralelo $24^{\circ} \mathrm{S}$.

\section{MATERIAL E MÉTODOS}

O cultivar Pedrinhas (IAC 25) foi obtido pelo método genealógico (ALLARD, 1960), proveniente de seleção do híbrido 1910, originário do cruzamento entre a linhagem IRN 331-73, oriunda da Rodésia, com a denominação 'Zambezi', de porte anão, introduzida através do "International Spring Wheat Rust Nursery" de 1973 e o cultivar IAC 5 (Maringá), resultante do cruzamento Frontana/Kenya 58//Ponta Grossa 1 (CAMARGO, 1972). O 'Pedrinhas' apresenta as seguintes características: altura entre 80 e $90 \mathrm{~cm}$, ciclo precoce de $110-115$ dias da emergência à colheita, aurícula verde-amarelo-clara, a folha, de posição 
intermediária, de tonalidade clara e panícula creme, aristada e fusiforme, com comprimento aproximado de $9,5 \mathrm{~cm}$ e grãos castanho-avermelhados, ovóides (Figura 1).

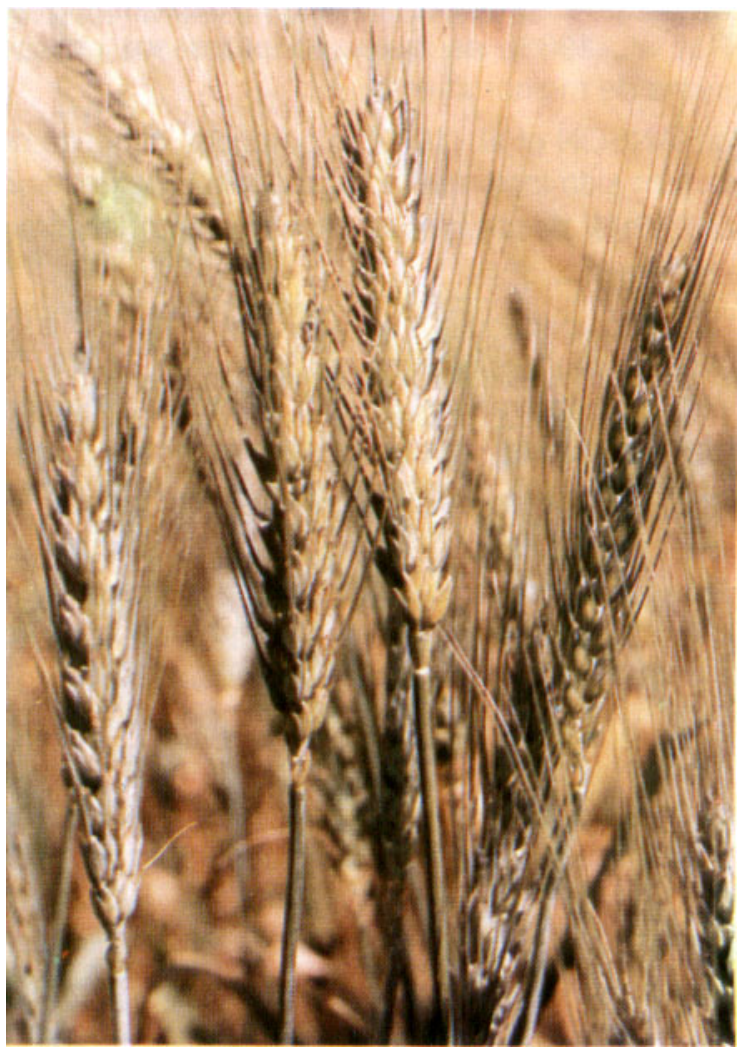

FIGURA 1. Espigas características do cultivar Pedrinhas, com aristas longas, em fase de granaçăo.

O cultivar Taiamã (IAC 161) é uma linhagem selecionada no Instituto Agronômico de Campinas, proveniente do híbrido Kavkas/Gavilan//Tito "S" CM 80817-C-10Y-2M-1Y-OM, originário do Centro Intemacional de Melhoramento de Milho e Trigo (CIMMYT) - México. O 'Taiamā' apresenta as seguintes características: altura da planta entre 70 e $80 \mathrm{~cm}$, ciclo médio de 125-130 dias da emergência à colheita, hábito vegetativo ereto; aurícula verde-amarelo-clara, folhas de posiçāo intermediária, verde-acinzentadas, panicula creme, claviforme; arista inexistente ou somente apical, com comprimento de $9,9 \mathrm{~cm}$ e grāos de cor creme (Figura 2). 


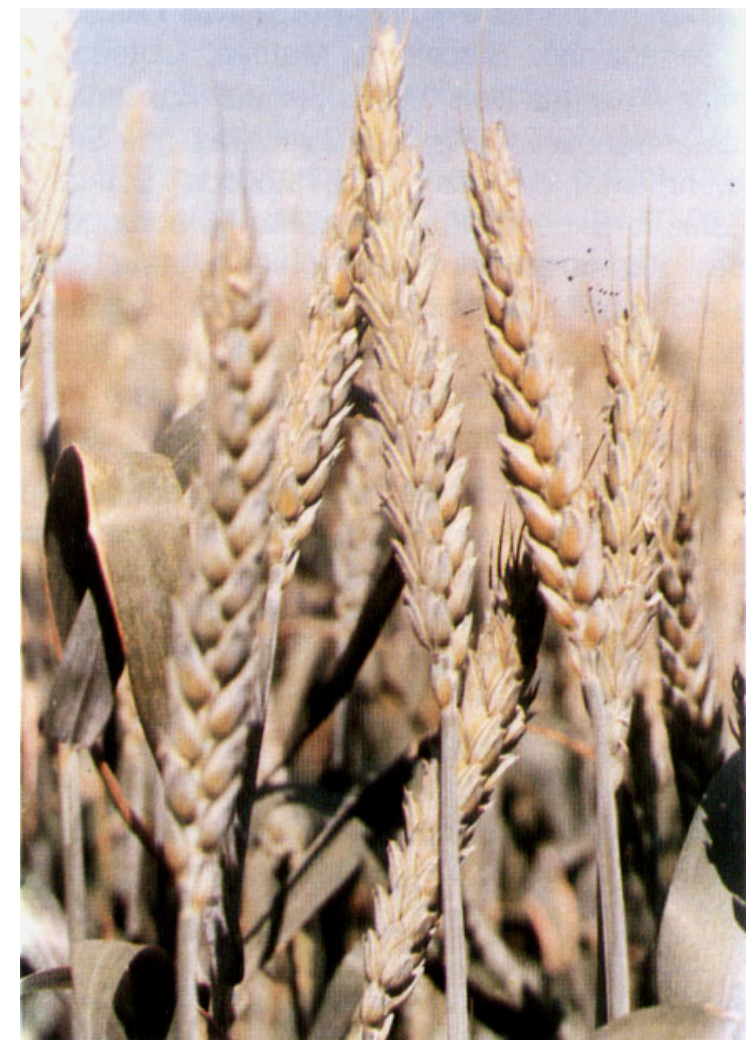

FIGURA 2. Espigas características do cultivar Taiamā, sem aristas ou microaristas, em fase de granação.

No período de 1983-88, na regiâo tritícola paulista do Vale do Paranapanema (oeste do Estado) instalaram-se, em condiçōes de sequeiro, vinte e cinco experimentos, com o objetivo de avaliar o comportamento do 'Pedrinhas', e onze experimentos, em 1983-85, para avaliar o 'Taiamä', abrangendo os seguintes municipios: Maracaí e distrito de São José das Laranjeiras, Palmital, Cruzália e distrito de Pedrinhas Paulista. Os dois tipos foram compostos pelos cultivares Pedrinhas e Taiamã, respectivamente, mais o testemunha 'Anahuac', com alta suscetibilidade ao alumínio tóxico (CAMARGO \& FELíCIO, 1986). Empregou-se delineamento estatístico de blocos ao acaso com quatro repetiçōes por local, sendo cada parcela constituida de cinco linhas de $5 \mathrm{~m}$ de comprimento, espaçadas de $0,20 \mathrm{~m}$, com uma separaçāo lateral de $0,60 \mathrm{~m}$ entre as parcelas. Procedeu-se à semeadura com 80 sementes viáveis por metro de sulco, efetuando-se a colheita da área total das parcelas, ou seja, $5 \mathrm{~m}^{2}$. 
Nas áreas de irrigação por aspersão, instalaram-se 26 experimentos para avaliaçāo do cultivar Pedrinhas e 35 para o cultivar Taiamã, nos municípios de Guaíra (Fazenda Sertāozinho, Barcelona, Mateiro, Lagoa do Fogão e Ponte Queimada), Colômbia (Fazenda Dois Imãos), Aguai (Fazenda Santa Lúcia), Jaborandi (Fazenda Santa Genoveva), Pirassununga (Fazenda São Domingos), Campinas (Centro Experimental de Campinas), Mococa (Estação Experimental) e Paranapanema (Estaçăo Experimental Holambra II), abrangendo solos com elevada e baixa acidez. Adotou-se delineamento semelhante ao usado nos ensaios de sequeiro. Para a comparação da produção média de grãos, separaram-se os ensaios de acordo com o solo onde foram realizados (alta ou baixa acidez). Foram considerados solos com alta acidez aqueles com saturação por bases $(\mathrm{V} \%$ ) inferior a $60 \%$ e, com baixa acidez, os com $\mathrm{V}$ maior que $60 \%$.

Anteriormente à instalação de cada experimento, retiraram-se amostras compostas dos solos, cujas análises foram efetuadas pela Seção de Fertilidade do Solo e Nutriçāo de Plantas do IAC. Os experimentos receberam adubação a lanço constante de $20 \mathrm{~kg}$ de $\mathrm{N}, 60 \mathrm{~kg}$ de $\mathrm{P}_{2} \mathrm{O}_{5}$ e $20 \mathrm{~kg}$ de $\mathrm{K}_{2} \mathrm{O}$, por hectare, nas formas de sulfato de amônio, superfosfato simples e cloreto de potássio respectivamente.

Para o estudo do comportamento dos cultivares em relação à ferrugem-do-colmo, Puccinia graminis f. sp. tritici, e ferrugem-da-folha, Puccinia recondita $f$. sp. tritici, avaliaram-se as plântulas no Centro Nacional de Pesquisa de Trigo, de acordo com os critérios do quadro 5 e, em plantas adultas em condiçóes de campo, pela escala modificada de Cobb, empregada no "International Rust Nursery" e utilizada por SCHRAM et al. (1974): é composta por um número estimando a porcentagem de ataque de moléstias no colmo e/ou na folha, acrescido de letra simbolizando o tipo de reaçāo, a saber: $\mathrm{S}=$ suscetivel; $\mathrm{MS}=$ moderadamente suscetivel; $\mathrm{M}=$ intermediário; $\mathrm{MR}=$ moderadamente resistente e $\mathrm{R}=$ resistente. Utilizou-se o 'BH-1146' como controle nos testes de reação à femugem-do-colmo. Para a helmintosporiose, ocorrente nas folhas, estimaram-se as infecçöes em porcentagem de área foliar infectada, observando-se as folhas superiores.

Os cultivares IAC 161 e IAC 25 foram testados para tolerância a 0, 2, 4, 6,8 e 10mg/litro de $\mathrm{Al}^{3+}$ em soluçōes nutritivas, mantendo-se constante a temperatura de $22^{\circ} \mathrm{C}$ (CAMARGO, 1983), e também para a tolerância a $0,11,300,600$ e $1.200 \mathrm{mg} /$ litro de $\mathrm{Mn}^{2+}$ em soluçōes nutritivas (CAMARGO \& OLIVEIRA, 1983) e a $0,56,5,10,20$ e $40 \mathrm{mg} /$ litro de $\mathrm{Fe}^{2+}$ em soluçōes nutritivas (CAMARGO \& FREITAS, 1985). Em todos os testes, utilizaram-se como controles os cultivares $\mathrm{BH}-1146$ (tolerante à toxicidade de $\mathrm{Al}^{3+}$ e sensivel à de $\mathrm{Mn}^{2+}$ e $\mathrm{Fe}^{2+}$ ) e Siete Cerros (sensivel à toxicidade de $\mathrm{Al}^{3+}$ e tolerante à de $\mathrm{Mn}^{2+}$ e $\mathrm{Fe}^{2+}$ ).

Para a irrigaçāo, adotou-se o método proposto por SILVA et al. (1984): consiste em uma irrigação de 40-50 mm após semeadura, com a finalidade de umedecer o solo, e a instalação de tensiômetros em pontos diferentes, à profundidade de $12 \mathrm{~cm}$. Efetuaramrse as irrigaçōes complementares quando a média 
das leituras dos tensiômetros apresentava 0,6 atm., determinando-se a lâmina líquida aplicada através da evaporação acumulada no tanque classe $\mathrm{A}$, entre os intervalos das irrigaçōes.

Os grãos de trigo dos cultivares Pedrinhas e Taiamã foram submetidos inicialmente a testes de moagem, para determinaçāo das características de rendimento de farinha. Utilizou-se, para tal, o moinho Buhler, modelo MLU-202, trabalhando-se com $5 \mathrm{~kg}$ de grãos para cada moagem. Os grãos tiveram sua umidade ajustada de acordo com o método oficial ARBEITSGEMEINSHALT (1971). Na moagem, determinou-se o rendimento de farinha, farelo grosso e farelo fino.

As farinhas obtidas da moagem foram submetidas a análises de ordem física no farinógrafo, amilógrafo e extensógrafo conforme AACC (1969). Determinaram-se o teor e a qualidade do glúten e o "falling-number" segundo BÄR (1982), e o expansograma, consoante o método oficial ARBEITSGEMEINSHALT (1971).

Para os testes de panificação, utilizou-se a formulação descrita por VITTI et al. (1982), e preparou-se o pão do tipo francês de 80 gramas de massa por unidade, segundo o método descrito por VITTI et al. (1980). Compararam-se os päes com os preparados com farinha comercial, sendo a avaliação efetuada de acordo com VITTI \& PIZZINATTO (1975).

\section{RESULTADOS E DISCUSSÃO}

Os rendimentos médios de grãos obtidos nos experimentos em condição de sequeiro, no Vale do Paranapanema, com o 'Pedrinhas' em 1983-88, e o 'Taiamã', em 1983-85, ambos em comparação com o 'Anahuac', encontram-se respectivamente nos quadros 1 e 2 .

Verificaram-se, pela análise conjunta dos dados dos dois tipos, efeitos significativos para anos e interaçāo cultivares $x$ anos, porém nāo para cultivares.

QUADRO 1. Produçð̌es médias de grãos obtidas nos ensaios efetuados em condiçð̃es de sequeiro no Vale do Paranapanema, SP, empregando-se o cultivar Pedrinhas, no período $1983-88$

\begin{tabular}{lrrrrrrrr}
\hline Cultivares & 1983 & 1984 & 1985 & 1986 & 1987 & 1988 & Media \\
\hline & & & & $\mathrm{kg} / \mathrm{ha}$ & & & \\
\cline { 2 - 4 } & $879 \mathrm{a}$ & $858 \mathrm{~b}$ & $1967 \mathrm{~b}$ & & $1489 \mathrm{a}$ & $2457 \mathrm{a}$ & $1974 \mathrm{~b}$ & $1604 \mathrm{a}$ \\
Anahuac & $710 \mathrm{a}$ & $1270 \mathrm{a}$ & $2491 \mathrm{a}$ & $1517 \mathrm{a}$ & $2503 \mathrm{a}$ & $2354 \mathrm{a}$ & $1807 \mathrm{a}$ \\
Pedrinhas & 3,79 & $16,0^{*}$ & $7,05^{\star}$ & 0,02 & 0,05 & $6,2^{*}$ & 3,35 \\
\hline $\mathrm{F}$ (cultivar) & 26,76 & 23,72 & 21,67 & 32,27 & 18,56 & 19,97 & 11,27 \\
CV $(\%)$ & & &
\end{tabular}

Médias para a comparaçáo da produçáo de gráos entre cultivares dentro de cada ano seguidas pela mesma letra năo diferem estatisticamente.

* Significativo ao nivel de $5 \%$ pelo teste $\mathrm{t}$. 
QUADRO 2. Produçס̋es médias de grăos obtidas nos ensaios de sequeiro na regiăo do Vale do Paranapanema, SP, empregando-se o cultivar Taiamă, no perlodo 1983-85

\begin{tabular}{lrrrrr}
\hline Cultivares & 1983 & 1984 & & 1985 & Média \\
\cline { 2 - 4 } & & & & & \\
Anahuac & $958 \mathrm{~b}$ & $1076 \mathrm{a}$ & & $2238 \mathrm{a}$ & $1424 \mathrm{a}$ \\
Taiamă & $1126 \mathrm{a}$ & $799 \mathrm{~b}$ & $2053 \mathrm{a}$ & $1326 \mathrm{a}$ \\
\hline F (cultivar) & $4,29^{*}$ & $9,72^{*}$ & 2,24 & 0,52 \\
CV $(\%)$ & 21,23 & 23,22 & 16,27 & 12,08 \\
\hline
\end{tabular}

Médias para a comparaçăo da produçăo de grăos entre cultivares dentro de cada ano seguidas pela mesma letra náo diferem estatisticamente.

- Significativo ao nivel de $5 \%$, pelo teste $t$.

Apesar de não ocorrer diferença significativa entre ambos quanto à produção de grãos, o 'Pedrinhas' firmou como grande vantagem o ciclo precoce em relaçäo ao 'Anahuac', que exibiu um ciclo médio.

As produções médias de grãos dos ensaios empregando-se o cultivar Pedrinhas, em condição de irrigação por aspersão, em solos com baixa e alta acidez, encontram-se no quadro 3.

A análise estatística conjunta dos ensaios conduzidos em solos com alta acidez no periodo 1983-88 mostrou efeitos significativos para cultivares e anos e năo-significativos para a interaçăo cultivares $x$ anos. O 'Pedrinhas' $(2949 \mathrm{~kg} / \mathrm{ha})$ diferiu significativamente do 'Anahuac' $(2521 \mathrm{~kg} / \mathrm{ha})$, indicando que o primeiro apresentou boa adaptação às condiçōes do solo com elevada acidez.

A análise estatística conjunta dos ensaios conduzidos em solos com baixa acidez mostrou efeito năo-significativo para cultivares e significativos para anos e interação cultivares $x$ anos.

O quadro 4 apresenta as produçōes de grãos dos experimentos instalados em solos com alta e baixa acidez,empregando-se o 'Taiamä' em condição de irrigaçăo, em 1983-88.

Pela análise conjunta dos ensaios em solos com elevada acidez,verificaram-se efeitos significativos para cultivares, anos e interação cultivares $x$ anos. O 'Taiamä' (2923kg/ha) diferiu em produção de grãos do 'Anahuac' (2586kg/ha) nessas condiçōes. Nos ensaios em solos com baixa acidez, não se detectou efeito significativo para cultivares, porém, sim, para anos e interação cultivares $x$ anos.

Tais resultados demonstram que, em condiçăo de irrigaçāo, empregando-se solos com elevada acidez, destacaram-se os cultivares Pedrinhas e Taiamã e, para solos com baixa acidez, os cultivares Anahuac, Taiamã e Pedrinhas. 


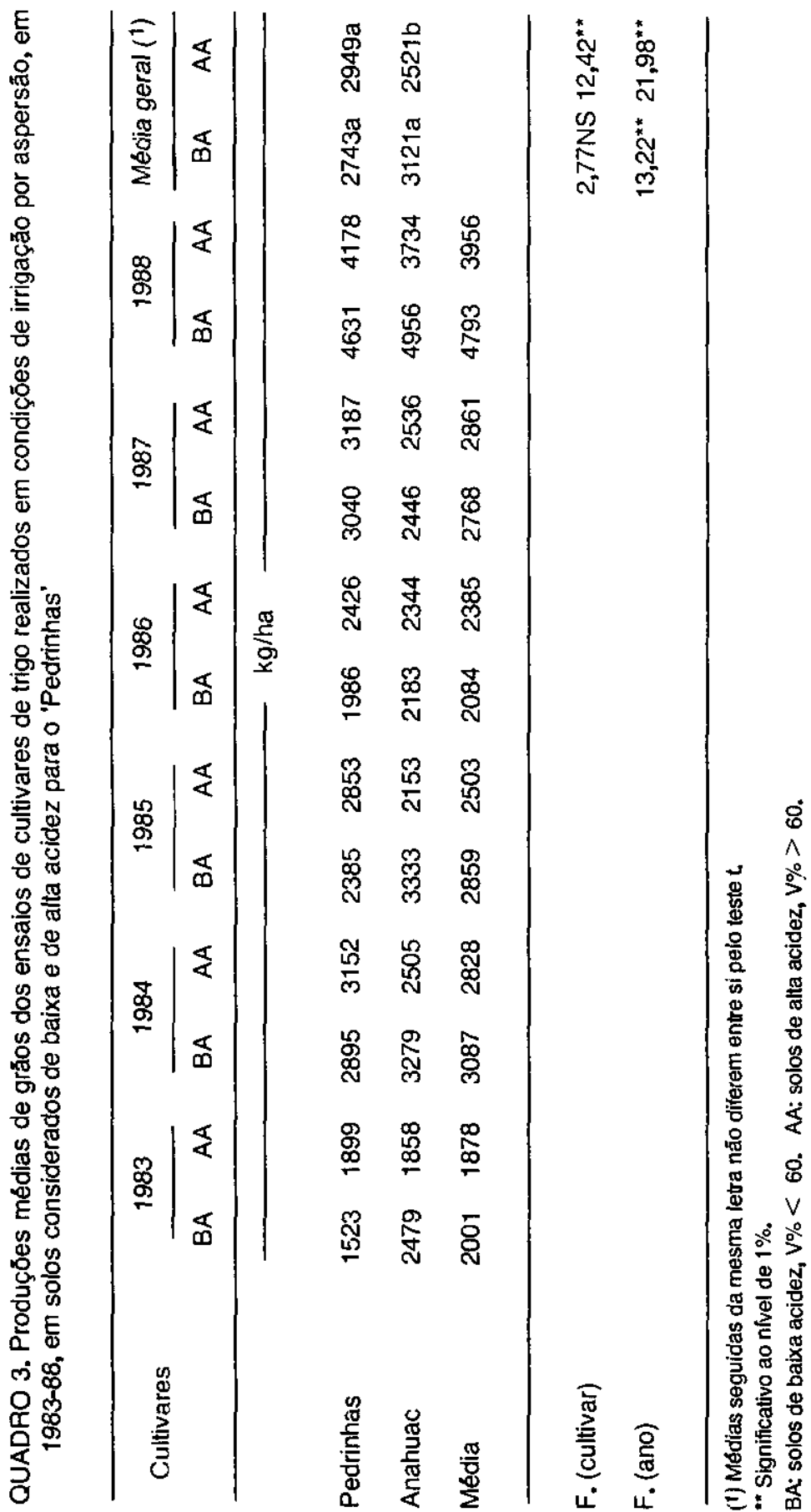




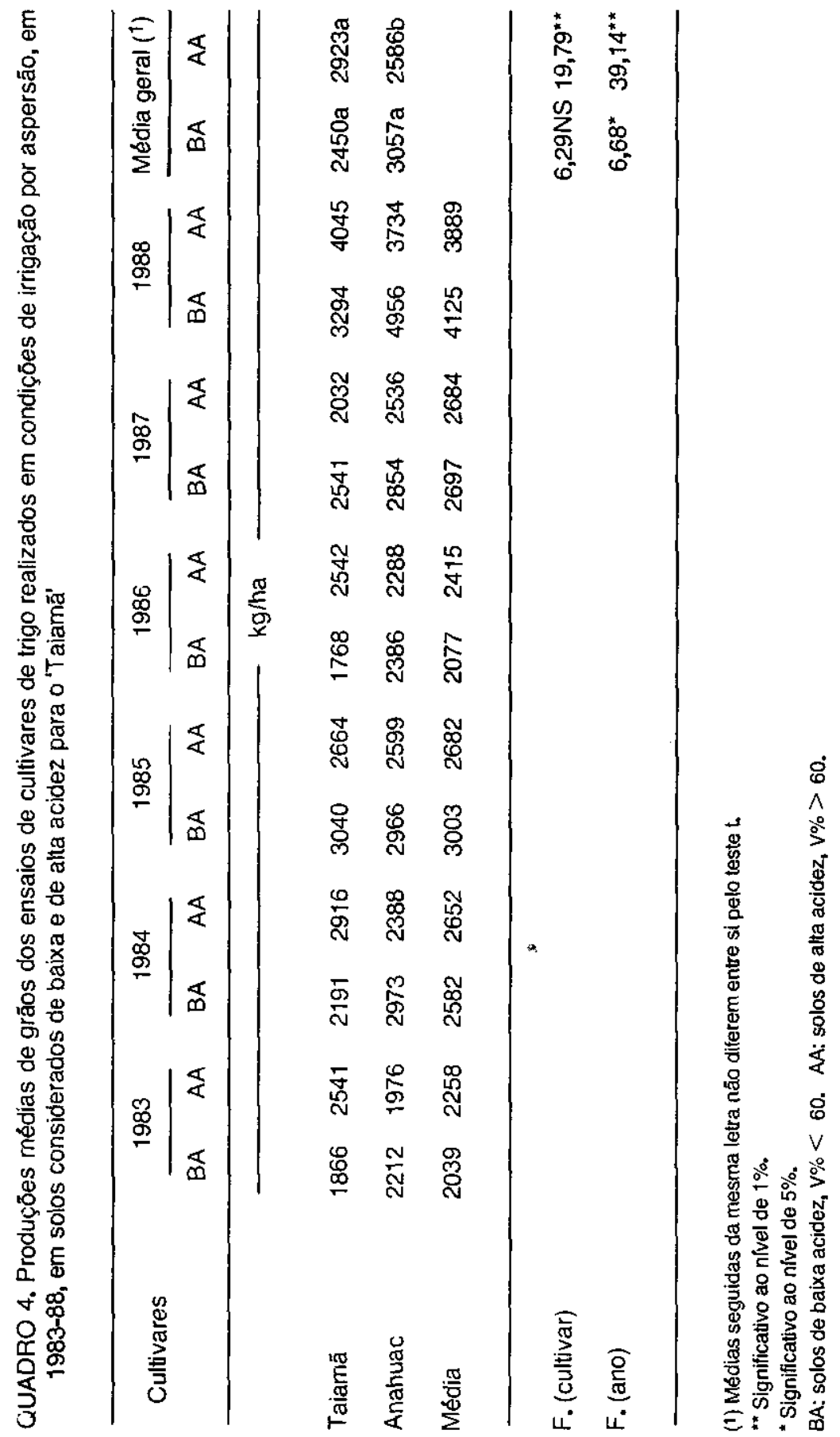


Os resultados da avaliação dos novos cultivares quanto à resistência à Puccinia graminis f. sp. tritici em casa de vegetaçāo encontram-se no quadro 5. O 'Taiamā' apresentou resistência à dez raças identificadas desse patógeno, bem como o cultivar Anahuac. O 'Pedrinhas' mostrou suscetibilidade às raças G19, G20, G21 e G24 e, o 'BH-1146', a todas as raças testadas.

Na região do Vale do Paranapanema, prevalece a cultura de sequeiro, em maior área no Estado de São Paulo. As reaçōes dos novos cultivares em condição de campo, à ferrugem-do-colmo e da-folha e à helmintosporiose encontram-se no quadro 6 . As duas últimas ocorreram com maior intensidade ao longo dos anos em estudo. $O$ 'Pedrinhas' apresentou-se mais suscetivel à ferrugem-da-folha, enquanto, para a helmintosporiose, os três mostraram-se mais ou menos suscetíveis, de acordo com 0 ano em estudo, estando a variação dessa ocorrência correlacionada com as condiçōes climáticas locais (FELíCIO et al., 1986).

Nas regiōes paulistas do norte, com irrigação por aspersão - Quadro 7 - verificou-se baixa incidência das ferrugens e ocorrência da helminthosporiose mais acentuada, pois há tendência de a umidade relativa do ar e da planta manter-se mais constante.

O comprimento médio de dez raizes dos cultivares de trigo Taiamã e Pedrinhas e dos controles (BH-1146 e Siete Cerros), medido após 72 horas de crescimento nas soluçōes nutritivas completas que se seguiu de 48 horas de crescimento nas soluçōes de tratamento contendo seis diferentes concentraçōes de alumínio $(0,2,4,6,8$ e $10 \mathrm{mg} /$ litro), encontram-se no quadro 8 .

QUADRO 5. Reaçăo de cultivares de trigo às raças de Puccinia graminis f. sp. tritici, em casa de vegetação, no estádio de plântula

Raças de Puccinia graminis t. sp. tritici

Cultivares

\begin{tabular}{llllllllll}
\hline G11 & G15 & G17 & G18 & G19 & G20 & G21 & G22 & G23 & G24
\end{tabular}

\begin{tabular}{lllllllllll}
\hline Anahuac & $1-$ & $1-$ & $0 ;$ & $0 ;$ & 2 & 0 & 1 & $1-$ & $0 ;$ & $0 ;$ \\
BH-1146 & 4 & 4 & 4 & 4 & 3 & 4 & 4 & 4 & 4 & 4 \\
Pedrinhas & 1 & $1-$ & 1 & 1 & 3 & 3 & 3 & $1-$ & 2 & 3 \\
Taiama & $0 ;$ & $0 ;$ & $0 ;$ & $0 ;$ & $0 ;$ & 1 & $0 ;$ & $0 ;$ & $0 ;$ & 1 \\
\hline
\end{tabular}

Escala de leitura adotada : $0=$ imune; 0,1 e 2 = resistente; $2+$ e 2++ = moderadamente resistente; 3 e 3-- = moderadamente suscetivel; 3 e 4 = suscetivel.

Fonte: Centro Nacional de Pesquisa de Trigo. 
QUADRO 6. Reaçoes médias de cultivares de trigo em relaçăo à ferrugem-do-colmo e da-folha e à helmintosporiose em 1983/88 na regiăo do Vale do Paranapanema em trigo de sequeiro

\begin{tabular}{|c|c|c|c|c|c|c|c|c|c|c|c|c|}
\hline \multirow[t]{2}{*}{ Cultivares } & \multicolumn{4}{|c|}{ F. colmo } & \multicolumn{4}{|c|}{ F. folha } & \multicolumn{4}{|c|}{ Helmintosporiose } \\
\hline & 83 & 85 & 87 & 88 & 83 & 85 & 87 & 88 & 83 & 85 & 87 & 88 \\
\hline Anahuac & 0 & 0 & 0 & 0 & $10 S$ & $10 S$ & $5 S$ & $10 S$ & 40 & 20 & 25 & 30 \\
\hline Pedrinhas & $20 S$ & 0 & 0 & 0 & $40 S$ & $5 S$ & $20 S$ & $10 S$ & 30 & 20 & 35 & 30 \\
\hline Taiamå & 0 & 0 & - & - & 5MS & $5 M S$ & - & - & 40 & 20 & - & - \\
\hline
\end{tabular}

Obs: Devido às condiçớes climáticas desfavoráveis à oconencia de moléstias, năo houve incidência em 1984 e 1986.

Nas soluções de tratamento contendo $\mathrm{Al}^{3+}$, todos os cultivares reduziram 0 crescimento radicular em relação ao das soluçōes de tratamento contendo Omg/litro de $\mathrm{Al}^{3+}$. O 'Siete Cerros' revelou-se muito sensivel ao $\mathrm{Al} 3+$, uma vez que suas raizes primárias não cresceram em soluçāo com alumínio. Os demais exibiram crescimento das raizes primárias, mesmo na concentrção mais elevada, $10 \mathrm{mg} / \mathrm{litro}$ de $\mathrm{Al} 3+$. Como o ' $\mathrm{BH}-1146$ ' apresentou as raizes mais compridas nessa concentração, foi considerado tolerante e, os demais, moderadamente tolerantes.

No quadro 9, encontra-se o comprimento médio das ralzes dos cultivares de trigo medidos após doze dias de crescimento em soluçōes nutritivas con tendo cinco concentraçōes de ferro.

Os resultados confirmaram ser o ' $\mathrm{BH}-1146$ ' muito sensivel à toxicidade causada por altas doses de ferro. Nesse ensaio, houve uma redução de $69 \%$ no crescimento das suas raízes, à medida que se aumentaram as concentraçōes de ferro de 0,56 para $40 \mathrm{mg} /$ litro. Também demonstrou alta suscetibilidade o 'Taiamã', com uma redução no sistema radicular de $65 \%$. O 'Siete Cerros' apresentou-se como tolerante e, o'Pedrinhas', como moderadamente tolerante,com reduçōes de 48 e $58 \%$, respectivamente, no comprimento das raizes.

O comprimento médio das raizes dos cultivares de trigo medidos após quinze dias de crescimento em soluçōes contendo diferentes concentraçōes de manganês encontra-se no quadro 10.

Seus resultados confirmaram a elevada suscetibilidade do ' $\mathrm{BH}-1146$ ' à toxicidade de manganês em doses elevadas, mostrando uma redução de $84 \%$ no crescimento das ralzes à medida que se elevaram as concentraçóes de manganês nas soluçōes de 0,11 para 1.200mg/litro. Os cultivares Siete Cerros; Taiamã e Pedrinhas exibiram tolerância, mostrando reduçōes no sistema radicular entre 62 e $68 \%$ nas mesmas condiçöes. 


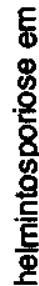

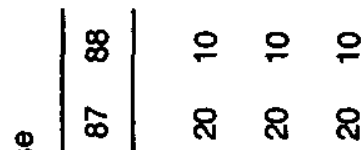

œ 8 \&

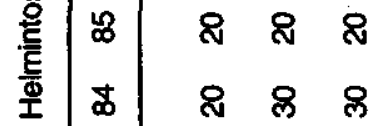



옹

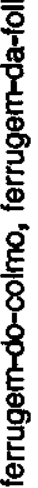

$\boldsymbol{\infty}$

ल ले ल

○ 으

$\circ 00$

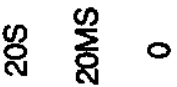

$\circ \stackrel{\text { O }}{\circ}$

$\circ \stackrel{\circ}{\circ}$

ณ \& -

통 $\frac{5}{9}$

은

옹용

电

눈

릉

ष

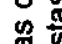

윽

룡

$\$$

8

苋

ᄄ

요

용

옹

空

|




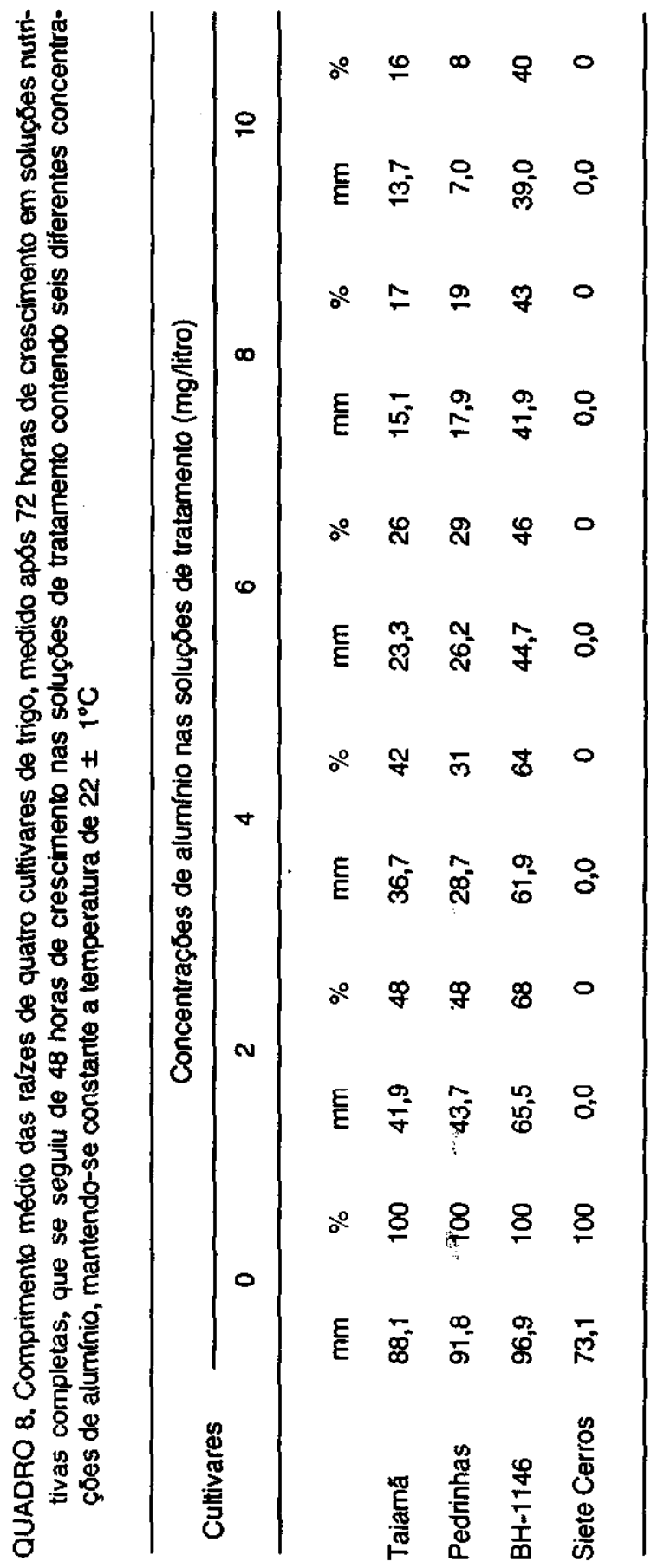




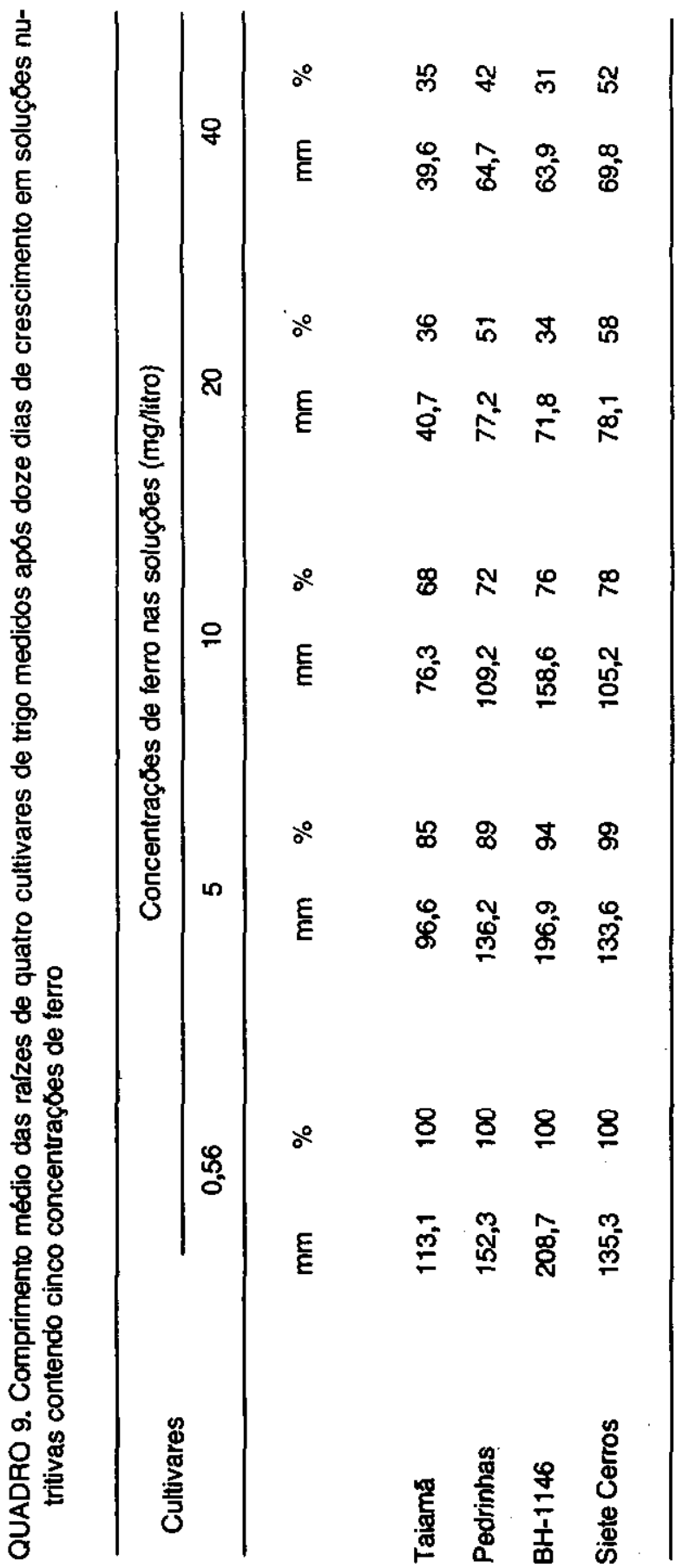




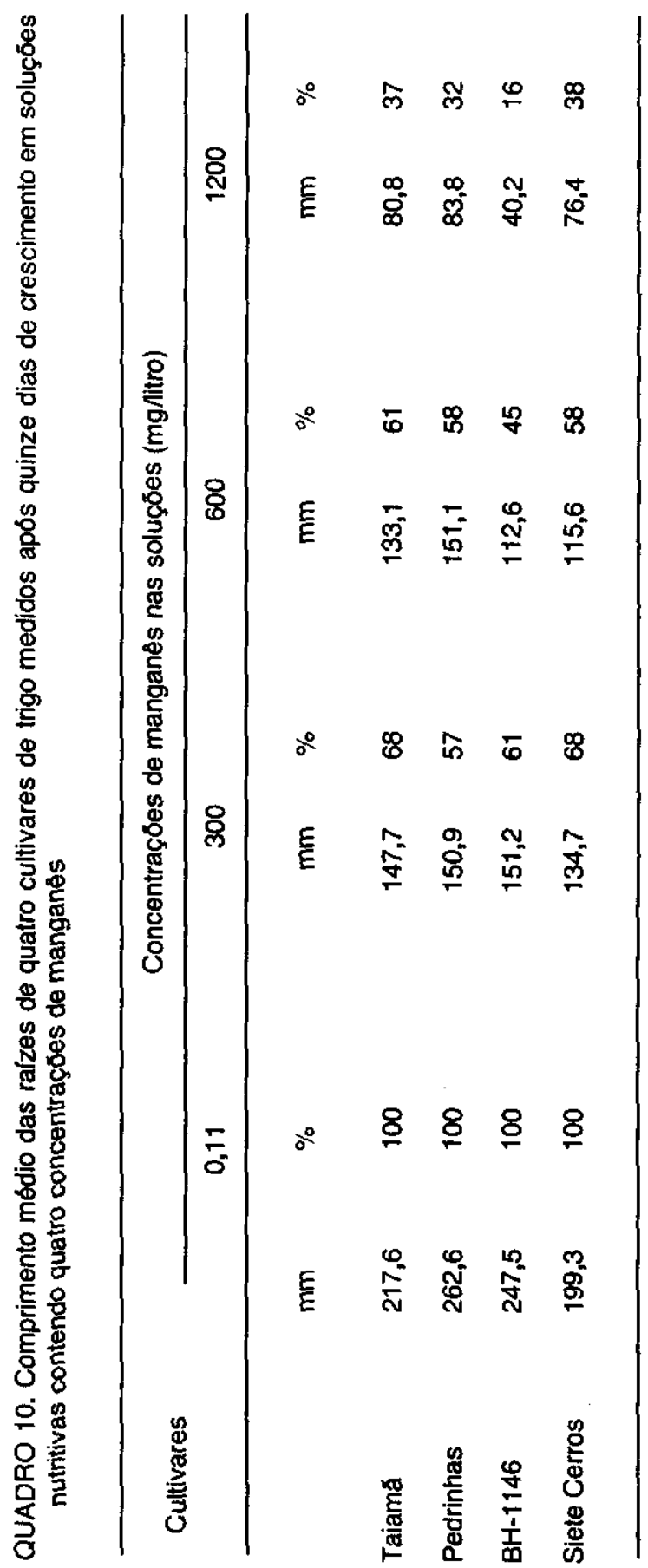


Os cultivares Pedrinhas e Taiamã foram submetidos a teste de moagem cujos resultados se acham no quadro 11: o primeiro apresentou melhor desempenho em termos de extração de farinha. Geralmente, no moinho utilizado, Buhler piloto, os valores de rendimento em moagem são menores. Os cultivares nacionais tendem a apresentar tipo de grãos mais moles, característica essa que mostra maiores dificuldades no processo de moagem.

Com relação às características físicas da farinha, como teor de glúten e qualidade, nota-se que o Pedrinhas, apesar do teor razoavelmente bom de glúten, a qualidade deste não foi boa. O Taiamã apresentou bom teor de glúten e de qualidade considerada boa. O teste "falling number", que se relaciona com a atividade enzimica da farinha, mostrou, para ambos, valores altos, indicando pouquissima atividade. O Taiamä apresentou valor mais alto, o que, em termos de panificação, significa pão de miolo seco; entretanto, pode-se adicionar à farinha enzima amilolítica para sanar essa caracteristica.

Os valores do farinógrafo e amilógrafo - Quadro 12 - mostram o alto valor de absorção de água pela farinha do 'Taiamã', podendo indicar que o glúten é de melhor qualidade, como demonstrado no quadro 11 . Em relação à resistência, que significa a maior ou menor capacidade de se alterar com a açăo mecânica das pás da batedeira, o melhor comportamento foi para o 'Pedrinhas'. Contudo, esse problema pode ser superado pelo uso de aditivos, que aceleram o processo de maturação do glúten. Quanto ao abrandamento, isto é, perda de consistência da massa após certo tempo na batedeira, o 'Taiamã' comportou-se com valores de 50 unidades farinográficas Brabender. Para a característica viscográfica de suspensão da farinha de trigo em água, o 'Pedrinhas' revelou a maior viscosidade máxima, a quente; no entanto, próxima à do 'Taiamä', que reflete, da mesma forma que no "falling number", a tendência do miolo mais seco, indicando pouca atividade enzímica. Nota-se que, para as demais caracteristicas obtidas no amilógrafo, não houve diferenças a salientar.

QUADRO 11. Características ffsicas da farinha de trigo dos cultivares Pedrinhas e Taiamå

\begin{tabular}{lcccc}
\hline Cultivares & R.M. & T.G.U. & Q.G. & F.N. \\
\hline \multirow{3}{*}{ Pedrinhas } & $\%$ & $\%$ & $\mathrm{~cm}^{3}$ & seg. \\
Taiamă & 67,52 & 24,8 & 6 & 422 \\
Farinha comercial & 65,00 & 30,0 & 18 & 561 \\
& - & 30,0 & 18 & 540 \\
\hline
\end{tabular}

R.M. = rendimento de farinha na moagem. T.G.U. = teor de glúten úmido. Q.G. = qualidade do glúten. F.N. = "falling number", teste relacionado com a atividade enzímica da farinha.

Obs: Como a farinha foi obtida no comércio, năo há valor de rendimento na moagem. 
Com relaçāo à extensibilidade da massa - Quadro 13 - após 153 minutos de descanso, o 'Taiamā' apresentou maior resistência à deformação, indicando ter reação favorável à adição de melhoradores do tipo oxidante, segundo BLOKSMA (1964). As caracteristicas expansográficas demonstram que houve maior retenção no'Taiamã.

QUADRO 12. Características farinográficas e amilográficas da farinha de trigo dos cultivares Pedrinhas e Taiamá

\begin{tabular}{|c|c|c|c|c|c|c|c|c|}
\hline \multirow{2}{*}{ Cultivares } & \multicolumn{5}{|c|}{ Farinograma } & \multicolumn{3}{|c|}{ Amilograma } \\
\hline & T.D. & R. & $\mathrm{E}$. & A. & $A B$. & T.G. & V.M. & T.V.M. \\
\hline & $\min$ & $\min$ & $\min$ & U.F. & $\%$ & ${ }^{\circ} \mathrm{C}$ & U.F. & ${ }^{\circ} \mathrm{C}$ \\
\hline Pedrinhas & $2: 30$ & $11: 00$ & $8: 30$ & 60 & 59,14 & 60,0 & 1245 & 90,0 \\
\hline Taiamã & $6: 00$ & $7: 00$ & $1: 00$ & 50 & 68,00 & 59,5 & 1060 & 90,0 \\
\hline Farinha comercial & $5: 00$ & 8:00 & $3: 00$ & 50 & 65,00 & 60,0 & 1050 & 90,0 \\
\hline
\end{tabular}

T.D. = tempo de desenvolvimento. R. = resisténcia. E. = estabilidade. A. = abrandamento, em unidade farinográfica. $\mathrm{AB}$. = absorçăo de água. T.G. = temperatura de gelatinizaçăo. V.M. = viscosidade máxi$m_{1}$ a quente, em unidades farinográficas. T.V.M. = temperatura de viscosidade máxima.

QUADRO 13. Características expansográficas e extensográficas de farinha de trigo dos cultivares Pedrinhas e Taiamã

\begin{tabular}{|c|c|c|c|c|c|c|}
\hline \multirow{2}{*}{ Cultivares } & \multicolumn{4}{|c|}{ Extensografo } & \multicolumn{2}{|c|}{ Expansógrafo } \\
\hline & R. & E. & $\mathrm{RZ}$ & A. & C.P. & ES. \\
\hline & & & & $\mathrm{cm}^{2}$ & $\mathrm{~mm}$ & $\mathrm{~mm}$ \\
\hline Pedrinhas & 514 & 145,6 & 3,40 & 145,6 & 79,8 & 65,5 \\
\hline Taiamã & 470 & 124,0 & 3,79 & 86,9 & 67,0 & 116,0 \\
\hline Farinha comercial & 520 & 122,0 & 4,01 & 132,0 & 80,0 & 102,0 \\
\hline
\end{tabular}

R. = resistência em unidades extensográficas Brabender. E. = extensibilidade. $R Z=$ razắo. A. =área.

C.P. = capacidade de produçấo de $\mathrm{CO}^{2}$. ES.= estabilidade da massa. 
Nenhum dos métodos reológicos ou químicos empregados isoladamente é capaz de predizer exatamente o comportamento de determinada farinha em relação ao seu comportamento na panificação. Esses processos são indicadores das tendências das farinhas. Dessa forma, o método teste é o de panificação. Pelo quadro 14, verifica-se que o melhor comportamento é do Taiamã', principalmente com respeito ao volume especifico. Com relaçäo às características intemas e externas do păo, dadas pelos valores da contagem total comparativa, pode-se observar uma semelhança nos cultivares estudados.

QUADRO 14. Caracterlsticas dos pares obtidos com farinha de trigo dos cultivares Pedrinhas e Taiamã

\begin{tabular}{lcc}
\hline \multicolumn{1}{c}{ Cultivares } & V.E.C. & C.T.C. \\
\hline & $\%$ & $\%$ \\
Pedrinhas & 98,3 & 100,0 \\
Taiamă & 119,0 & 101,0 \\
Farinha comercial & 100,0 & 100,0 \\
\hline
\end{tabular}

V.E.C. = volume especffico comparativo. C.T.C. $=$ contagem total comparativa.

\section{CONCLUSÕES}

1. Os cultivares de trigo Pedrinhas e Taiamã não apresentaram diferença na produtividade de grāos em comparação ao 'Anahuac' em condiçōes de sequeiro, na região do Vale do Paranapanema, confirmando o primeiro a vantagem quanto ao ciclo precoce (100-115 dias).

2. No norte paulista, em solo de alta acidez ( $\mathrm{V} \%<60)$, em conciiçōes ce irrigação por aspersão, os cultivares Pecirinhas e Taiamã foram superiores em produtividade à testemunha, 'Anahuac'. Em solos com porcentagem de saturaçäo por bases superior a 60 não houve diferenças na produçāo de grãos.

3. Os cultivares Pedrinhas e Taiamã mostraram-se moderadamente tolerantes à toxicidade de $\mathrm{Al}^{3+}$. $\mathrm{O}$ 'Taiamă' foi sensivel e o 'Pedrinhas' mostrou moderada tolerância à toxicidade de ferro. Os dois cultivares exibiram tolerância moderada à toxicidade de manganês.

4. O cultivar Pedrinhas apresentou-se mais suscetivel à ferrugem-da-folha que o 'Taiamä' em condiçōes de campo. Para a helmintosporiose ambos foram suscetiveis, variando essa condiçāo de acordo com o ano em estudo. 
5. O 'Taiamã̉, do ponto de' vista de panificaçāo, comportou-se melhor que o 'Pedrinhas', comparados à amostra de trigo comercial de valor 100 .

6. Apesar das diferenças obtidas nos testes de panificação, os cultivares em estudo podem ser considerados aptos para tal finalidade, mesmo levando-se em consideraçāo que o 'Pedrinhas' produziu pães com volume específico inferior de 1,7\%, comparado à amostra comercial.

\section{REFERENCIAS BILBIOGRAFICAS}

ALLARD, R.W. Principles of plant breeding. New York, John Wiley, 1960. 381p.

AMERICAN ASSOCIATION OF CEREAL CHEMISTS, AACC. Methods of analysis of AACC. St. Paul, Minn., 1969.

ARBEITSGEMEINSCHALT fuer Getreidefosfhung Standart fuer Geitreideund. Brot. Detmold, Ed. Moritz Schaefer, 1971. 138p.

BÄR, W.R. Análise e avaliaçăo do trigo e dos produtos derivados. Campinas, ITAL, 1982. $154 p$.

BLOKSMA, A.H. Rheology and chemistry of dough. In: POMERAMZ, Y., ed. Wheat: chemistry and techonology. Saint Paul, Minn., AACC, 1964. 821p.

CAMARGO, C.E.O. Efeito de temperatura enri soluçăo nutritiva na tolerância ao alumínio de cultivares de trigo. Brayantia, Campinas, 42:51-63, 1983.

- Estudos de variedados de trigo para o Estado de São Paulo. Piracicaba, Escola Superior de Agricultura "Luiz de Ciueiroz", 1972. 102p. Tese (Doutoramento)

\& FELíCIO, J.C. Melhoramento genético do trigo no instituto Agrono :o. O Agronónico, Campinas, 38(3):213-228, 1986.

\& FREITAS, J.G. Tolerância de cultivares de trigo a diferentes niveis de ferro em soluçáo nutritiva. Bragantiá, Campinas, 44(1):65-75, 1985.

\& OLIVEIRA, O.F. Tolerância de cultivares de trigo a diferentes niveis de manganês em solução nutritiva. Bragantia, Campinas, 42:65-78, 1983.

FELICIO, J.C.; BARROS, B.C.; CAMARGO, C.E.O. \& BÄR, W.H. Maracal (IAC 17) e Xavantes (IAC 18): cultivares de trigo para o Estado de Săo Paulo. Bragantia, Campinas, 42(1):15-25, 1983.

FELICIO, J.C.; CAMARGO, C.E.O.; BARROS, B.C. \& VITTI, P. Iguaçu (IAC 21) e Araguaia (IAC 22): cultivares de trigo de sequeiro para o Estado de Såo Paulo. Bragantia, Campinas, 44(1):115-128, 1985. VITTI, P. Tocantins (IAC 23 ) e Tucurul (IAC 24): novos cultivares de trigo. Eragantia, Campinas, 47(1):93-107, 1988.

; FREITAS, J.G.; FERREIRA FILHO, A.W.P.; BARROS, B.C. \& CAMARGO, M.B.P. Avaliação de genótipos de trigo para a regiāo do Vale do Paranapanema no quadriénio 1981-84. Bragantia, Campinas, 45(2):257-277, 1986. 
HANSON, H.; BORLAUG, N.E. \& ANDERSON, R.G. Trigo en el Tercer Mundo. México, Centro Internacional de Mejoramiento de Maiz y Trigo, 1982. 166p.

OSÓRIO, E.A. Variedade e melhoramento. In: FUNDAÇĀO CARGILL. Trigo no Brasil. Campinas, 1982. v.1, p.147-197.

SCHRAM, W.; FULCO, W.S.; SOARES, M.H.G. \& ALMEIDA, A.W.P. Resistência de cultivares de trigo em experimentaçăo ou cultivo no Rio Grande do Sul, às principais doenças füngicas. Agronoritia Sulriograndense, Porto Alegre, 10:31-39, 1974.

SILVA, A.R. Melhoramento das variedades de trigo destinadas às diferentes regibes do Brasil. Rio de Janeiro, Ministério da Agricultura - Serviço de Informaçåo Agrícola, 1966. 82p. (Estudos Técnicos, 33)

SILVA, E.M. da; LUCHIARI JÚNIOR, A; GUERRA, A.F. \& GOMIDE, R.L. Recomendaçăo sobre o manejo de irrigaçăo em trigo para a regiāo dos Cerrados. In: REUNIĀO DA COMISSÃO NORTE-BRASILEIRA DE PESGUISA DE TRIGO, 10., Campinas, 1984. Brasnia, EMBRAPA-CPAC, 1984. 60p.

VITTI, P; LEITÄO, R.F.F.; PIZZINATTO, A. \& PENTEADO, R.L.B. Preparo de uma farinha de milho integral e desengordurada e seu uso em produtos de panificaçăo. Boletim do ITAL, Campinas, 17(4):451-467, 1980.

; MOREIRA, R.T. \& BĀR, W.H. Estudo tecnológico do cultivar de trigo nacional IAC 18. Boletim do ITAL, Campinas, 19(2):183-194, 1982.

\& PIZZINATTO, A. Emprego da farinha de raspa de mandioca, pré-gelatinizada em påo e biscoito. Coletânea do ITAL, 6:409-429, 1975. 